\title{
Competences of Mathematics Teachers in Diagnosing Teaching Situations and Offering Feedback to Students: Specificity, Consistency and Reification of
}

\section{Pedagogical and Mathematical Discourses}

Summary of "Biza, I., Nardi, E., \& Zachariades, T. (2018). Competences of mathematics teachers in diagnosing teaching situations and offering feedback to students: Specificity, consistency and reification of pedagogical and mathematical discourses. In T. Leuders, J. Leuders, \& K. Philipp (Eds.), Diagnostic Competence of Mathematics Teachers. Unpacking a complex construct in teacher education and teacher practice, (pp. 55-78). New York: Springer."

\section{What is it about?}

At the heart of secondary mathematics lessons, are key moments in which learners' mathematical thinking can lead to rich discussions about important mathematical ideas. Those moments are called by Leatham, Peterson, Stockero and Van Zoest (2015) ${ }^{1}$ Mathematically Significant Pedagogical Opportunities to build on Student Thinking (MOSTs). MOSTs are very crucial moments that, if recognized by teachers, can be utilized to create great learning opportunities. Our tasks invite teachers to engage with situations which satisfy key characteristics of MOSTs: they create pedagogical opportunities that may motivate students' mathematical thinking and raise significant mathematical questions.

In this study, we provide insights into teachers' skills in diagnosing MOSTs and in offering constructive feedback to their students. For this purpose, we use the Tangent task- $N$ [Link to Tangent task-N] which addresses common views about the tangent line: A line is tangent to a curve if there is one and only one common point between the line and that curve; and the tangent line keeps the curve in one side of it. These beliefs are correct in some cases, but not in all: for example, in the case of a tangent at inflection point of a curve, the tangent crosses the curve and splits it in two parts. The Tangent Task- $N$ brings the latter case to participants' attention by asking for their feedback on a dialogue between a teacher and a student responding to the question: Is $y=2$ a tangent to $f(x)=3 x^{3}+2$ ? The student's initial answer is algebraic but it fails to offer adequate proof of why the line is tangent, as it is merely based on the fact that there is only one common point $A(0,2)$ between the line and the curve. Then, the teacher challenges the response by asking: "[t]he parabola $y=x^{2}$ and the line $x=0$ have only one common point, the point $(0,0)$. Is the line $x=0$ tangent of the parabola at this point?" The student sketches the parabola and the line on the board and concludes that "it isn't, because the line cuts the parabola at this point". When, the teacher asks the student to rethink the initial problem the student sketches the graphs of both $y=2$ and $f(x)=3 x^{3}+2$ and concludes that "[a]s we see from the graph, the line $y=2$ cuts the curve $y=3 x^{3}+2$ at the point $(0,2)$. So, the line is not a tangent of this curve". The teacher agrees with this conclusion and invites the student to justify the response algebraically. We invited 23 mathematics graduates enrolled in a postgraduate mathematics education programme, many already in-service teachers, to: solve the mathematical problem; examine the solution proposed by the student; examine the teacher's response to the student; and describe the approach they would

\footnotetext{
${ }^{1}$ Leatham, K.R., Peterson, B.E., Stockero, S.L., \& Van Zoest, L.R. (2015). Conceptualizing mathematically significant pedagogical opportunities to build on student thinking. Journal for Research in Mathematics Education, 46(1), 88-124.
} 
adopt in this classroom situation. Key results of the analysis of the responses are presented in the next section.

Key Results:

- There is a great variation in the participants' competencies in diagnosing teaching issues and in addressing these issues in the feedback they offer to their students.

- This variation can be described in terms of a typology of four interrelated characteristics: consistency between stated beliefs/knowledge and intended practice, specificity of the response to the given classroom situation, reification of pedagogical discourse, and reification of mathematical discourse.

- There is variation in the consistency between beliefs and intended practice. Responses were either consistent, with elements of consistency but with incomplete actualization of the stated beliefs in the actual practice, or even inconsistent. In fact, about half of the responses showed elements of inconsistency.

- There is a great variation in the responses' specificity to the classroom situation, ranging from being highly specific to being peripherally related to the context of the teaching situation described in the task.

- Reification of key pedagogical discourse that participants have met in their postgraduate studies (i.e. terms like constructivism) varied from being essential in some responses to being redundant or inaccurate in others.

- Reification of key mathematics discourse that participants have met in their postgraduate studies varied from being essential in some responses to being less essential in others.

- Diagnosing and addressing issues pertaining to a particular teaching situation can be done with a sharp (or less so) focus. Achieving a sharp and effective focus on the given situation can be a challenge.

- An appropriately designed task, which addresses complex purposes, affords opportunity to engage with aspects of mathematics, didactical approaches, pedagogical theories and epistemological beliefs. We see all these aspects crucial in teachers' diagnostic proficiency when they deal with unexpected situations in the classroom.

- Our situation-specific task design and this typology of four interrelated characteristics can contribute towards the identification and development of mathematics teachers' diagnostic competencies. They can help teachers: recognise MOSTs; optimise these opportunities; and, transform their beliefs and knowledge into practice.

How to put these ideas into practice?

- Why not share the task in this paper with your colleagues and discuss it with them? What different responses did you and your colleagues come up with?

- Can you think of similar examples?

- Tell us your thoughts at @mathtask, https://www.uea.ac.uk/groups-andcentres/a-z/mathtask. 